\title{
Condition-Based Diagnostic Approach for Predicting the Maintenance Requirements of Machinery
}

\author{
C. I. UGECHI ${ }^{1}$, E. A. OGBONNAYA ${ }^{2}$, M. T. LILLY ${ }^{1}$, S. O. T. OGAJI ${ }^{3 *}$, S. D. PROBERT ${ }^{3}$ \\ ${ }^{1}$ Department of Mechanical Engineering, Rivers State University of Science and Technology, \\ Port Harcourt, Nigeria \\ ${ }^{2}$ Department of Marine Engineering, Rivers State University of Science and Technology, \\ Port Harcourt, Nigeria \\ ${ }^{3}$ School of Engineering, Cranfield University, Bedfordshire, U K \\ E-mail: S.OGAJI@CRANFIELD.AC.UK \\ Received January 10, 2009; revised February 21, 2009; accepted February 23, 2009
}

\begin{abstract}
Wise maintenance-procedures are essential for achieving high industrial productivities and low energy expenditure. A major part of the energy used in any production process is expended during the maintenance of the employed equipment. To ensure plant reliability and equipment availability, a condition-based maintenance policy has been developed in this investigation. In particular, this project explored the use of vibration parameters in the diagnosis of equipment failure. A computer-based diagnostic tool employing an artificial neural-network (ANN) was developed to analyse the ensuing machinery faults, their causes and consequences. For various categories of this type of machinery, a vibration-severity chart (ISO 12372 / BS 4675: 1971) appropriately colour coded according to defined mechanical faults, was used in training of the ANN. The model was validated using data obtained from a centrifugal pump on full load and fed into the program written in Visual Basic. The results revealed that, for centrifugal pumps within 15 to $300 \mathrm{kw}$ power range, vibration-velocity amplitude of between 0.9 and $2.7 \mathrm{~mm} / \mathrm{s}$ was within acceptable limits. When the values rose to between 2.8 and $7.0 \mathrm{~mm} / \mathrm{s}$, closer monitoring and improved understanding of the equipment condition was needed. The evolved diagnostic and prognostic model is applicable for other rotary equipment that is used within the same power limits.
\end{abstract}

Keywords: Condition Based, Diagnostic Model, Predictive Maintenance, Machinery, Centrifugal Pumps

\section{The Challenge}

Maintenance, although requiring the expenditure of significant amounts of energy, is usually required in order to keep (or restore) facilities at an acceptable operational standard [1]. For most plants, maintenance practice is predominantly based on routine-scheduled prevention as well as previously unanticipated reactions to overcome faults. Predictive maintenance (PdM) procedures, such as that devised in this project, are evolving and results in less wasted effort. According to Ogbonnaya [2], Contreras et al. [3] and Salva et al. [4] condition monitoring (CM) an aspect of PdM is defined as the use of appropriate technologies to determine the operational state of the considered machinery. For instance, it may involve vi- bration measurements, infrared thermography, and/or oil analyses etc.

For decades, conventional wisdom suggested that the best way to optimise the performance of physical assets was to overhaul or replace them at fixed interval (PM). This was based on the premise that there is a direct relationship between the amount of time (or number of cycles) equipment spends in service and the likelihood that it will fail. Moubray [5], stated that this relationship between running time (age) and failure is true for some failure modes, but that it is no longer very productive as equipment are now much more complex than it was even fifteen years ago. He pointed out that fixed interval overhaul ignores the fact that overhauls are extraordinarily invasive undertakings that massively upset stable 
systems. As such, they are likely to induce infant mortality, and so cause the very failure, which they seek to prevent.

This has led to startling changes in the patterns of equipment failure. Unless there is a dominant age-related failure mode, fixed interval overhauls or replacements do little or nothing to improve the reliability of rotary equipment [5]. There is no gain in overhauling a machine that has nothing wrong with it [6]. Moubray [5] concluded that "in the absence of any evidence to the contrary, it is more realistic to develop maintenance strategies which will assume that equipment failure can occur at any time and not at fixed amount of time in service".

\section{Maintenance Management}

Direct on-line real-time continual monitoring and analysis of machinery behavior is the most reliable way to achieve a high productivity [3]. If an abnormal situation can be detected early, when defects are minor and have not affected machine output, with the cause of the fault diagnosed while the machine is still running, then the downtime for associated repairs can be reduced and other attendant advantages achieved.

Figure 1 shows the various maintenance methods/ techniques/strategies. Reactive maintenance is usually only implemented following an unforeseen event leading to a partial or total failure of the system. Preventive maintenance (PM) is initiated according to a predetermined time-schedule in order to try to avoid the occurrence of failure. Predictive maintenance (PdM) is laun- ched as a result of behaviour of the equipment/ machinery before total failure, whereas proactive maintenance may require redesigning and/or modification of the adopted maintenance-procedure where necessary.

Each of these techniques has merits and frailties, but $\mathrm{PdM}$ is the most advantageous [7]; it combines the advantages of preventive and proactive strategies. Its basic

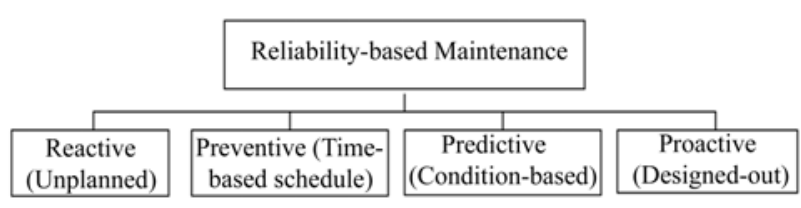

Figure 1. Maintenance procedures.

concept is shown in Figure 2. Predictive maintenance is summarized as involving actions taken to improve one or more of the following machinery characteristics: availability, reliability, maintainability, safety, efficiency etc as well as reduce energy waste and environmental pollution [4]. As a result, the implementation of PdM usually enables one to have sufficient lead-time to plan, schedule and make necessary repairs before the equipment would otherwise fail. So major breakdowns and costly downtime can then be avoided.

\subsection{Condition Monitoring}

This has long been practiced by maintenance personnel who relied on their innate senses of hearing, touch and sight, but the judgment and conclusions were often not reliable. All physical structures and machinery, that are associated with rotating components, give rise to vibration. The vibrations so generated by machinery have become a well-utilized parameter for assessment in CM. It is one of the most versatile techniques, which is capable of detecting about $70 \%$ of common mechanical faults associated with rotating machinery [6].

Machinery vibrations are complex, but can be measured, processed and their interpretation simplified in order to facilitate the implementation of recommended action [8]. According to Okah-Avae [9], rotating machinery produce vibration patterns, which repeat periodically and so have been found to be amenable to analysis.

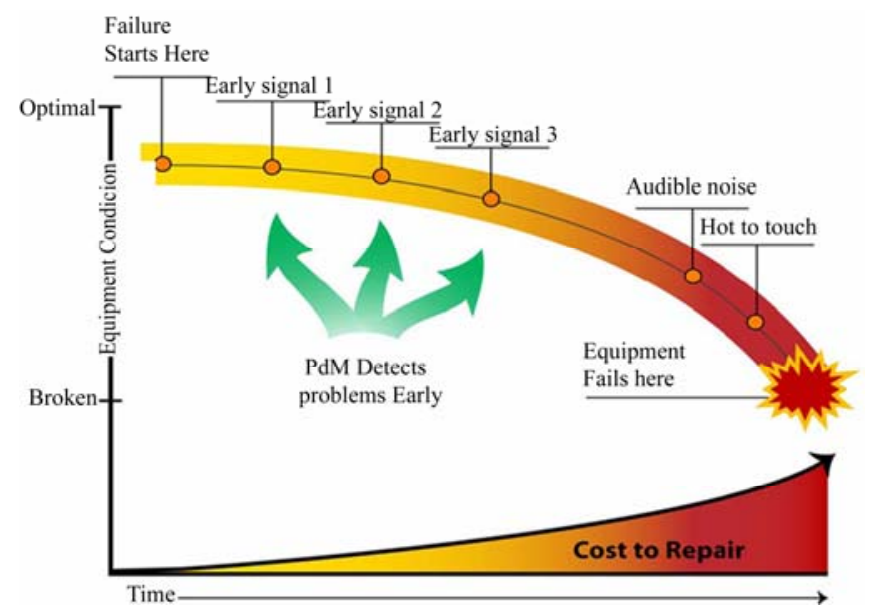

Figure 2. Basic behaviour of a failing system (machinery) [5]. 


\subsection{Vibration Monitoring and Analysis}

Even though the wise maintenance of industrial equipment may require the monitoring of additional parameters, such as temperature, pressure, flow, voltage, electric current, horsepower, torque, etc, vibration data usually contain more information about a machine's health and operating characteristics than any other parameter - see Table 1. This informed the choice of vibration monitoring and analysis over other condition monitoring techniques in this research.

Measurements of vibration parameters are important in many industrial applications. The parameters desired may be displacement, velocity, or acceleration; in time or frequency domain. These quantities are useful in predicting the fatigue failure of a particular component of machine and play important role in analysis, which are used to reduce equipment vibration [8]. According to Ralph [10], when measurement of both amplitude and frequency are available, diagnostic methods can be used to determine the magnitude of a problem and its probable cause.

Vibration severity is a function of displacement and frequency of rotation of the component. Measurements of vibration-velocity take into account both displacement and frequency: "vibration-velocity amplitude is a direct measure of vibration severity" [11]. Vibration-velocity gives an indication of vibration severity over a wide range of frequencies and hence is extensively applied in condition monitoring [9].

Each mechanical defect generates vibration in its own unique way [11]. This makes it possible to identify a mechanical problem by measuring and noting its vibration signature. When vibration measurements and analysis are performed systematically and intelligently, they will not only allow determination of machine health but also permit the prediction of the mechanical fault and when such condition most likely will have reached unacceptable levels [12].

Vibrations occurring in the 600 to $60,000 \mathrm{cpm}$ frequency range are generally described and measured by their vibration-velocity amplitudes [11]. In practice, the following relationships apply:

Displacement of vibrating component

$$
(x)=a /(2 \pi f)^{2}
$$

Velocity of vibrating component

$$
(v)=a / 2 \pi f
$$

Acceleration of vibrating component

$$
\text { (a) }=2 \pi f v
$$

\section{Research Methodology}

The identification of incipient faults in a machine, in order to diagnose an impending problem and locate the fault while the machine is still running, through an interpretation of its unique vibration characteristic (i.e. signature) is the main aim of PdM [13]. A good vibration survey program sets different limits for different machines, as well as different limits for different regions of the frequency domain spectra for the same machine.

The delineation of severity limits for good and bad bearing conditions are best determined by "comparison" or "trending" methods [11]. In establishing a program for checking the spike energy conditions of rolling element bearings; a "comparison method is used. The spike energy levels of similar machines are measured and any level which significantly departs from the average are singled out for further analysis of potential bearing problems. This method has led to the establishment of criteria levels which distinguished good and bad bearings.

Table 1. Parameters indicating the occurrence of faulty conditions in a rotating machine.

\begin{tabular}{|l|c|c|c|c|c|c|}
\hline PETECTED CONDITION & $\begin{array}{c}\text { PRESSURE } \\
\text { OF } \\
\text { OF MACHINE } \\
\text { PROCESS } \\
\text { FLUID }\end{array}$ & $\begin{array}{c}\text { FLOW } \\
\text { OF } \\
\text { FLUID }\end{array}$ & $\begin{array}{c}\text { OIL ANALY- } \\
\text { SIS }\end{array}$ & $\begin{array}{c}\text { SPIKE EN- } \\
\text { ERGY OF } \\
\text { BEARING }\end{array}$ & $\begin{array}{c}\text { VIBRATION } \\
\text { OF } \\
\text { MACHINE }\end{array}$ \\
\hline OUT- OF - BALANCE & & & & & & $\mathrm{X}$ \\
\hline MISALIGNMENT & $\mathrm{X}$ & & & & & $\mathrm{X}$ \\
\hline BENT SHAFT & $\mathrm{X}$ & & & & & $\mathrm{X}$ \\
\hline BOLL-BEARING DAMAGE & $\mathrm{X}$ & & & $\mathrm{X}$ & $\mathrm{X}$ & $\mathrm{X}$ \\
\hline GEAR DAMAGEAREARING DAMAGE & $\mathrm{X}$ & $\mathrm{X}$ & $\mathrm{X}$ & $\mathrm{X}$ & & $\mathrm{X}$ \\
\hline MECHANICAL LOOSENESS & & & & $\mathrm{X}$ & & $\mathrm{X}$ \\
\hline MECHANICAL RUBBING & & & & & & $\mathrm{X}$ \\
\hline NOISE & & & & & & $\mathrm{X}$ \\
\hline CRACKING & & & & & & $\mathrm{X}$ \\
\hline
\end{tabular}


Various ranges of vibration velocity amplitude and spike energy were represented with colour codes for corresponding level of vibration severity: green for good/normal condition, blue for acceptable condition, yellow for fair condition/ improvement required, and red for unacceptable condition. The use of a real-time recurrent simulation was therefore adopted in this investigation in order to develop an artificial neural-network (ANN) for the analysis of the vibration data [4].

\subsection{Artificial Neural-Networks (Anns)}

Ogbonnaya [8] showed that ANN is a promising tool to articulate and analyze the numerous data associated with catastrophic failures in rotating machinery. According to Agbese and Mohammed [14], since ANN, a branch of Artificial Intelligence (AI), are modelled after the biological neurons of the human brain, they hold considerable promise as building blocks in actualising the ultimate aim of AI systems. Out of the various architecture with which ANN is conveyed; the back propagation algorithm has proved most promising and accurate for analyzing machine vibration data [8]. Also of important is training the neuron of the network on the basis of pattern recognition; especially when there are large amount of data to handle.

Simulated neural networks are software models designed through suitable interpretation of the structure and basic function of the biological neuron of the human brain. Therefore the more physiology of the brain is understood the better the ability to design ANNs that will handle more complex problems. According to Carlton et al [15]; Agbese and Mohammed [14], the artificial neuron is called the processing elements or nodes, which are capable of handling information in response to external input. It has many input parts and combines the input

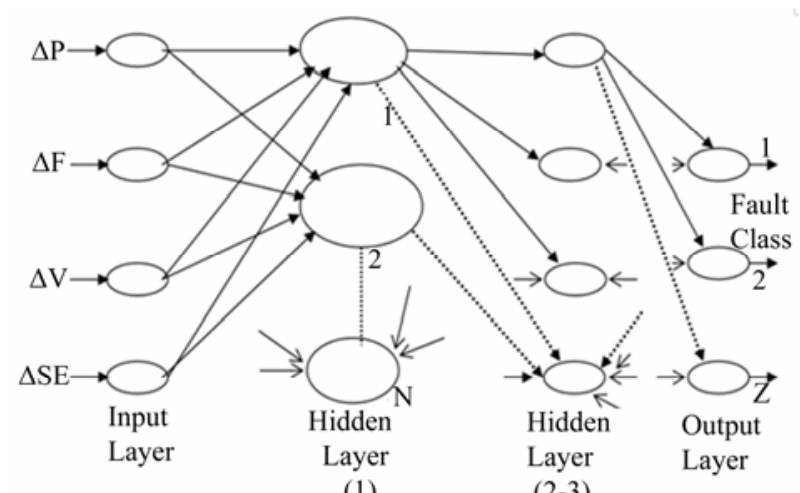

(1)

$(2-3)$

Legend: $\Delta \mathrm{P}$ - change in active power of driver; $\Delta \mathrm{F}$ - change in equipment's frequency; $\Delta \mathrm{V}$ - change in equipment's vibration-amplitude; $\Delta \mathrm{SE}$ - change in spike energy of bearing

Figure 3. Triple hidden-layer network. values it receives usually by summation. The combined input is then modified by a transfer function, which can be chosen to suit a particular application. This new value becomes the output and can be connected to the inputs of other processing elements through weighting functions, which correspond to the synaptic strength of biological neural connection $[15,16]$.

As in the biological brain, the neural network learns by altering the value of its weights. In a simulated neural network, the weights are altered as to reduce the error between the outputs the network produces in relation to a particular input pattern and the actual required outputs [15]. This is an iterative process, carried out as the patterns to be learnt are presented; an algorithm calculates the error and changes the value of the weights accordingly.

Typically, an engineering application of ANN technology consists of a set of input nodes that forms the input layer and one or more hidden layers. This type of ANN is called a multilayer perceptron, and usually a popular back-propagation algorithm is used to train the network [17].

The triple-hidden layer ANN shown in Figure 3 was designed with 4 nodes in the input layer. Hidden layer 1 is to be used for processing of the measured values; the summation is then passed to hidden layer 2 for exact fault-classification, while hidden layer 3 is designed to issue task specifications for achieving possible solutions. The output layer is therefore able to determine and display the nature of the exact fault and provide a solution for the fault to be overcome, thereby optimizing the use of energy and human resources.

A vibration-severity chart for various classes of machinery, as illustrated in Table 2, was used in the training of the network. Its inputs were vibration-velocity amplitude, motor power, equipment frequency and spike energy of the equipment. A computer program in Visual Basic (VB) was developed from the flowchart shown in Appendix 1. Further details of it are available from the authors. The faults considered included misalignment, imbalance, bent shaft, mechanical looseness, and poorbearing condition.

The diagnostic model is programmed according to various colour codes for corresponding pump conditions, diagnosed faults and appropriate task instructions on how to avert catastrophic failure of the vibrating equipment (in the considered case, a pump). The software flagged up defined information once the vibration values were within a specified range. The solutions obtained from the diagnostic model were used to determine how unwanted vibration problems could be eliminated or reduced to allowable limits.

When analysing vibration severity of a machine to pinpoint particular problem, it is essential to know the 
Table 2. Ranges of vibration severity for various classes of machinery (iso 12372 or bs 4675: 1971).

\begin{tabular}{|c|c|c|c|c|c|c|c|}
\hline \multicolumn{2}{|c|}{ Range of Vibration Severity } & \multicolumn{2}{|c|}{ Maximum Values } & \multirow{2}{*}{\multicolumn{4}{|c|}{ Class of Vibration of Machine }} \\
\hline \multirow{2}{*}{$\begin{array}{c}\text { Range } \\
\text { Classification }\end{array}$} & \multirow{2}{*}{$\begin{array}{c}\text { Effective } \\
\text { Velocity: } \\
\text { RMS } \\
(\mathrm{mm} / \mathrm{s})\end{array}$} & \multirow{2}{*}{$\begin{array}{c}\text { Vibration } \\
\text { Velocity } \\
(\mathrm{mm} / \mathrm{s})\end{array}$} & \multirow{2}{*}{$\begin{array}{c}\text { Vibration } \\
\text { Displacement } \\
(\mu \mathrm{m})\end{array}$} & & & & \\
\hline & & & & Class I & Class II & Class III & Class IV \\
\hline 0.28 & 0.28 & 0.4 & 1.25 & \multirow{3}{*}{ Good } & \multirow{4}{*}{ Good } & \multirow{5}{*}{ Good } & \multirow{6}{*}{ Good } \\
\hline 0.45 & 0.45 & 0.63 & 2 & & & & \\
\hline 0.71 & 0.71 & 1.0 & 3.15 & & & & \\
\hline 1.12 & 1.12 & 1.6 & 5 & \multirow{2}{*}{$\begin{array}{l}\text { Acceptable / } \\
\text { Allowable }\end{array}$} & & & \\
\hline 1.8 & 1.8 & 2.5 & 8 & & \multirow{2}{*}{$\begin{array}{l}\text { Acceptable / } \\
\text { Allowable }\end{array}$} & & \\
\hline 2.8 & 2.8 & 4.0 & 12.5 & \multirow{2}{*}{$\begin{array}{c}\text { Improvement } \\
\text { Required }\end{array}$} & & \multirow{2}{*}{$\begin{array}{l}\text { Acceptable / } \\
\text { Allowable }\end{array}$} & \\
\hline 4.5 & 4.5 & 6.3 & 20 & & \multirow{2}{*}{$\begin{array}{l}\text { Improvement } \\
\text { Required }\end{array}$} & & \multirow{2}{*}{$\begin{array}{c}\text { Acceptable / } \\
\text { Allowable }\end{array}$} \\
\hline 7.1 & 7.1 & 10 & 31.5 & \multirow{6}{*}{$\begin{array}{c}\text { Not } \\
\text { Acceptable }\end{array}$} & & \multirow{2}{*}{$\begin{array}{c}\text { Improvement } \\
\text { Required }\end{array}$} & \\
\hline 11.2 & 11.2 & 16 & 50 & & \multirow{5}{*}{$\begin{array}{c}\text { Not } \\
\text { Acceptable }\end{array}$} & & \multirow{2}{*}{$\begin{array}{c}\text { Improvement } \\
\text { Required }\end{array}$} \\
\hline 18.0 & 18 & 25 & 80 & & & & \\
\hline 28.0 & 28 & 40 & 125 & & & Not Acceptable & Not \\
\hline 45.0 & 45 & 63 & 200 & & & & Acceptable \\
\hline 71.0 & & & & & & & \\
\hline
\end{tabular}

Legend:

Class I: Small machines; electric motors up to $15 \mathrm{~kW}$ power.

Class II: Medium-size machines; electric motors of 15 to $300 \mathrm{~kW}$ power.

Class III: Large prime-movers or machines on rigid foundations; electric motors of above $300 \mathrm{~kW}$ power.

Class IV: Large prime-movers and other machines, Turbo Machines.

Good: Colour coded green.

Acceptable/Allowable: Colour coded blue.

Improvement Required: Colour coded yellow.

Not Acceptable: Colour coded red.

vibration frequency. Knowing the frequency helps in identifying the exact nature of the problem and the location of the faulty machine-component. Although all of the frequencies in a complex vibration signal can be of concern for analyzing machinery problems, the fundamental and dominant frequencies are of special importance. The fundamental frequency is equal to the speed of rotation of the rotating element - first harmonic (1* RPM). The dominant frequency is the frequency at which the largest vibration amplitude occurs. The fundamental and the dominant frequencies are not always the same. Where the dominant frequency differs from $1 *$ RPM (fundamental frequency), the dominant frequency is usually more in dicative of the trouble.

Therefore, during the analysis of the vibration data, interest was devoted primarily to measuring the dominant vibration amplitudes and determining the frequencies at which they occurred. This helped in the identification of the problem and isolation of the faulty machine component. High vibration amplitudes occurring at integral multiples of the machine's fundamental frequency (e.g. $2^{*}$ RPM, 3* RPM, 4* RPM, etc.) are associated to different failure modes.

\subsection{Instrumentation}

In undertaking this investigation, the following instruments were used: Vibration Data Collector (Model: IRD 880); Vibration Pick-Up Pen / Ear Piece; Laser Alignment Tools; Balancing Machine; Strobe Light; and a Computer System.

The vibration analyser performs the function of meters 


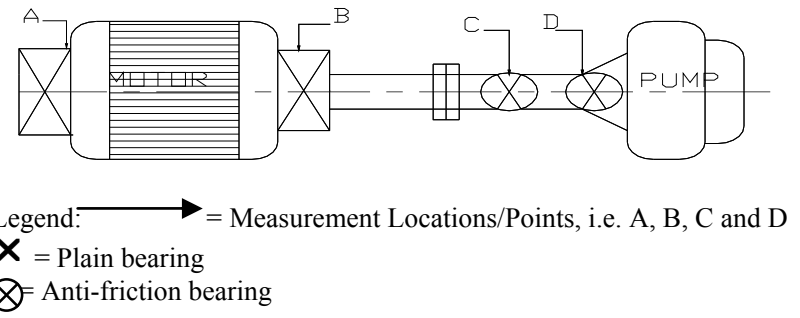

Figure 4. The tested pump assembly and location measuring points.

and monitors, and is capable of carrying out more complex operations. Vibration meters, monitors and analysers, uses vibration transducers. This is often referred to as vibration sensors or pick-up. The heart of the measurement system is the transducer; it is a sensing device which converts one form of energy to another. The vibration transducer converts mechanical vibration energy into electrical signal. The sensitivity of a velocity transducer is constant over a wide range of operating frequencies [11], but there are few limitations, which are above the scope of this work. The data collector is used in acquiring vibration-velocity, spike energy at variable frequencies. The rated power and frequency of the driver are used in the analysis as power at full load and fundamental frequencies. The data were collected manually and fed into the computer model for analysis.

\section{Results and Discussions}

Interpretation of the field-vibration data and the subsequent diagnosis of the failure mode, constituted the most difficult tasks in running the vibration-based program. Much depended on the experience and skill of the analyst. In undertaking maintenance, the need to avoid costly mistakes, minimize energy expenditure and achieve the benefits of PdM, led to the model developed for this investigation.

Vibration-velocity data, presented as root means square (RMS) values were collected, with the pump at full load - see Figure 4 and Table 3. The numerical values in Table 3 and trends on the associated graphs in Figure 5 displayed high axial and radial vibrations at locations $\mathrm{D}_{7}$ and $\mathbf{C}_{5}$ respectively, suffered by the pump bearings. Bearings A and B (see Figure 4) for the electric motor also experienced significant vibrations; although of lower amplitudes. Significant vibrations of the motor bearings could be transmitted through the shaft from bearings $\mathrm{C}$ and $\mathrm{D}$. Points $\mathrm{A}$ to $\mathrm{D}$ shown on Table 3 are the location points where vibration values were taken, while positions 1 to 8 represent the sequence in which data were collected on the same equipment at different frequencies.

Results of the analysis of data presented in Table 3 using the software model were displayed on the computer screen as in Figure 6. This indicated significant vibration amplitudes (depicted by the red and yellow colours). The program then proceeded to the second phase of the analysis in order to reveal the fault classifycations and task instructions, as shown in Figure 7. The analysis indicated the presence of high axial and radial vibrations at 1RPM, 2RPM, and 3RPM, which suggests misalignment, while the high spike energy at B was indicative of a defective bearing.

The misalignment originating at the driven end of the pump assembly was seen as the source of the failure because the vibration amplitude was largest there. The misaligned shaft and bearings at $\mathrm{C}$ and $\mathrm{D}$ led to the damage of the bearing at $\mathrm{B}$

Table 3. Vibration-analysis data sheet for unit 1800-01A pump.

\begin{tabular}{|c|c|c|c|c|c|c|c|}
\hline & & & & & & \multicolumn{2}{|c|}{ PUMP MAKE: GIABBIONETA } \\
\hline & & & & & & \multicolumn{2}{|c|}{ POWER: $36.5 \mathrm{~kW}$} \\
\hline & & & & & & \multicolumn{2}{|c|}{ RPM: $2950 / 2945$} \\
\hline & & & & & & \multicolumn{2}{|c|}{ DATE: $09 / 10 / 06$} \\
\hline & & & & & & \multicolumn{2}{|c|}{ ANALYZER MODEL: IRD 880} \\
\hline & & & & & & & \\
\hline MS/L & MS/S & $\begin{array}{c}\text { Frequency } \\
\text { cpm }\end{array}$ & $\begin{array}{c}\begin{array}{c}\text { Velocity (VH) } \\
\mathrm{mm} / \mathrm{sec}\end{array} \\
\text { (RMS) } \\
\end{array}$ & $\begin{array}{l}\text { Velocity (VV) } \\
\mathrm{mm} / \mathrm{sec} \\
\text { (RMS) } \\
\end{array}$ & $\begin{array}{c}\text { Velocity (VA) } \\
\mathrm{mm} / \mathrm{sec} \\
\text { (RMS) }\end{array}$ & $\begin{array}{c}\text { Spike Energy } \\
\text { g-SE }\end{array}$ & $\begin{array}{l}\text { Multiple of Fundametal } \\
\text { Frequency (cpm/2950) }\end{array}$ \\
\hline C & 5 & 3,012 & 8.2 & 1.1 & 1.0 & 0.0967 & 1 * RPM \\
\hline D & 7 & 3,066 & 4.7 & 1.6 & 9.8 & 0.076 & 1 * RPM \\
\hline B & 3 & 3,834 & 3.7 & 1.1 & 1.3 & 0.557 & $1 * \mathrm{rpm}$ \\
\hline A & 1 & 5,946 & 7.5 & 0.9 & 1.2 & 0.094 & 2 * rpm \\
\hline D & 8 & 8,007 & 3.0 & 2.7 & 0.9 & 0.1117 & 3 * rpm \\
\hline C & 6 & 12,730 & 1.9 & 3.6 & 1.1 & 0.1313 & 4 * rpm \\
\hline A & 2 & 13,686 & 1.9 & 1.1 & 1.3 & 0.097 & 5 * rpm \\
\hline B & 4 & 33,676 & 2.0 & 1.0 & 1.6 & 1.38 & $11 * \mathrm{rpm}$ \\
\hline
\end{tabular}




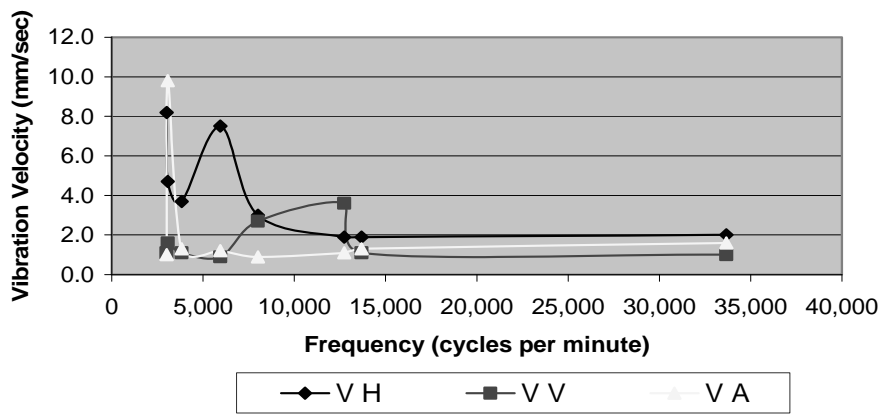

Figure 5. Vibration velocities for the 1800-01A pump.

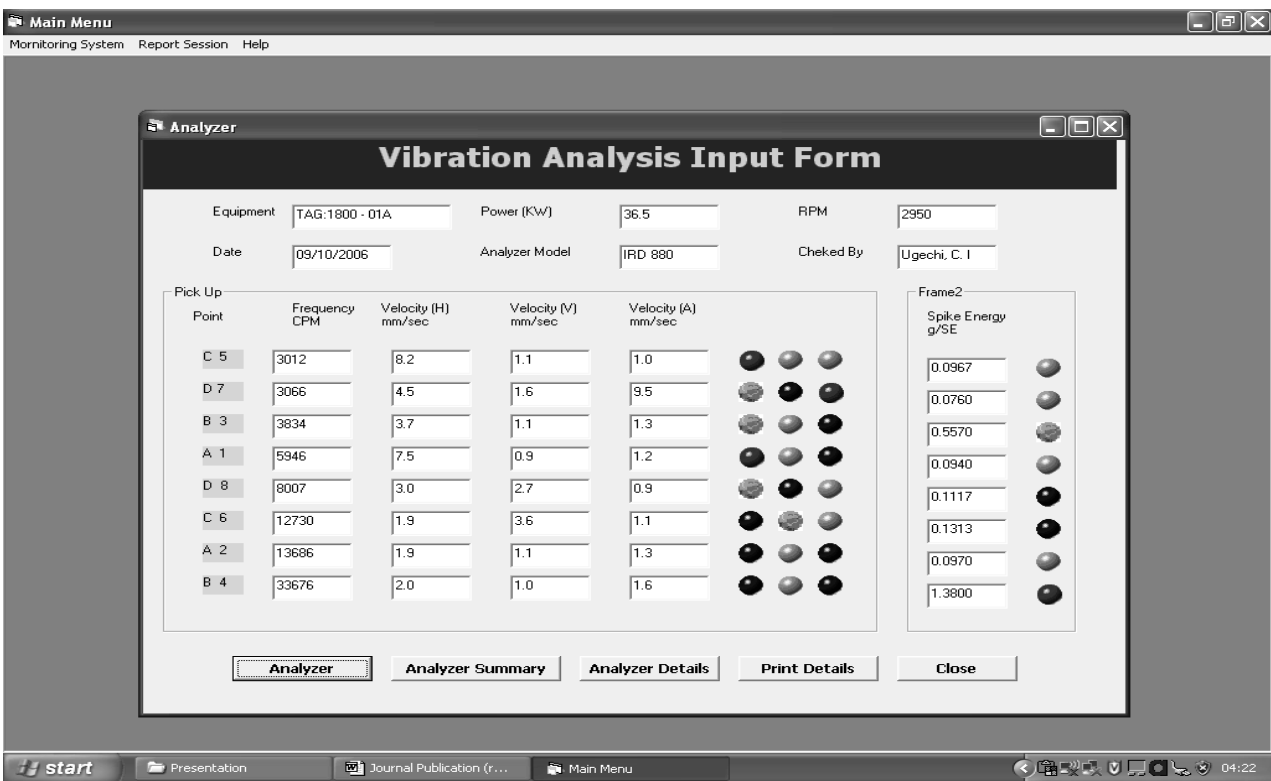

Figure 6. Computer screen presentation for $1^{\text {st }}$ phase of the analysis.

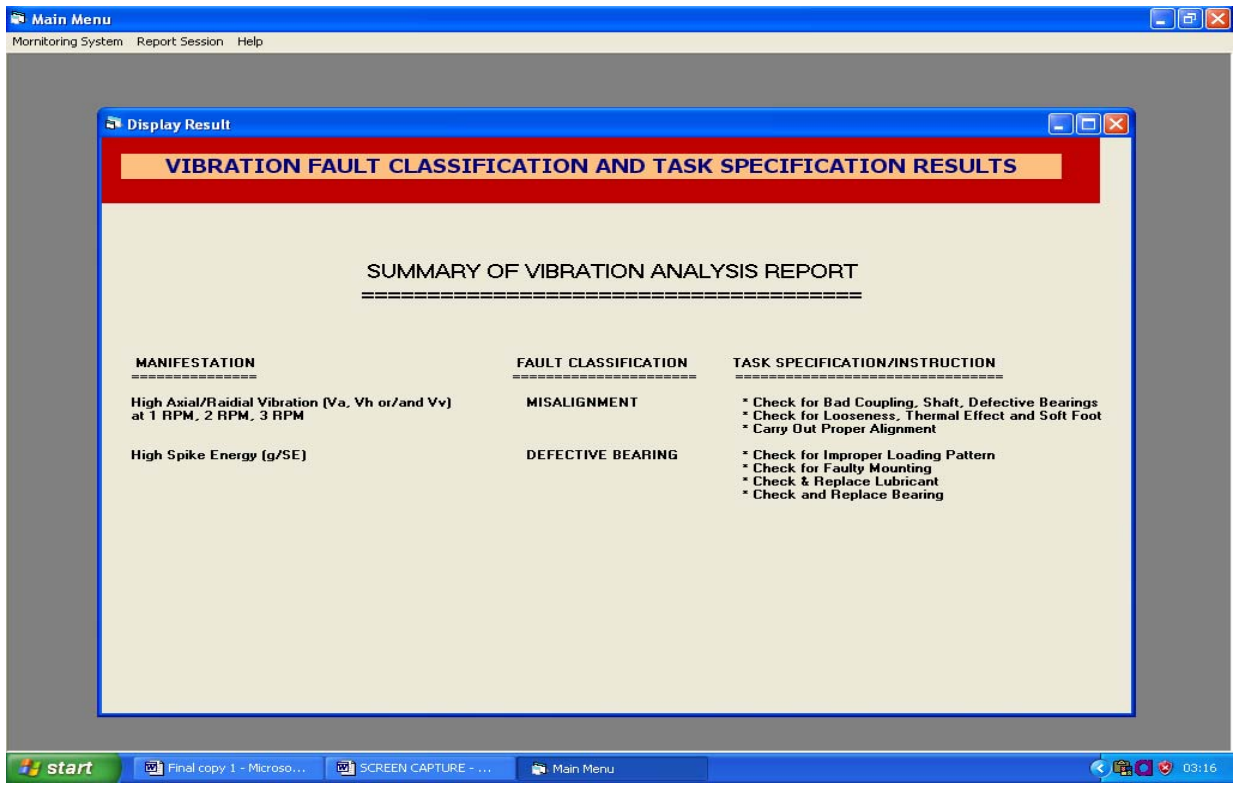

Figure 7. Computer screen presentation for $2^{\text {nd }}$ phase of the analysis. 
Table 4. Vibration-analysis data sheet for unit 1800-01A pump (AFE).

\begin{tabular}{|c|c|c|c|c|c|c|c|}
\hline & & & & & & \multicolumn{2}{|c|}{ PUMP MAKE: GIABBIONETA } \\
\hline & & & & & & \multicolumn{2}{|c|}{ POWER: $36.5 \mathrm{~kW}$} \\
\hline & & & & & & \multicolumn{2}{|c|}{ RPM: 2950 / 2945} \\
\hline & & & & & & \multicolumn{2}{|c|}{ DATE: $17 / 10 / 06$} \\
\hline & & & & & & \multicolumn{2}{|c|}{ ANALYZER MODEL: IRD 880} \\
\hline & & & & & & & \\
\hline MS/L & MS/S & $\begin{array}{c}\text { Frequency } \\
\text { cpm }\end{array}$ & $\begin{array}{l}\begin{array}{c}\text { Velocity (VH) } \\
\mathrm{mm} / \mathrm{sec}\end{array} \\
\text { (RMS) }\end{array}$ & $\begin{array}{l}\text { Velocity (VV) } \\
\mathrm{mm} / \mathrm{sec} \\
\text { (RMS) }\end{array}$ & $\begin{array}{c}\text { Velocity (VA) } \\
\mathrm{mm} / \mathrm{sec} \\
\text { (RMS) }\end{array}$ & $\begin{array}{c}\text { Spike Energy } \\
\text { g-SE }\end{array}$ & $\begin{array}{l}\text { Multiple of Fundametal } \\
\text { Frequency (cpm/2950) }\end{array}$ \\
\hline A & 1 & 1,500 & 2.5 & 2.6 & 1.3 & 0.07 & $0.5^{*} \mathrm{RPM}$ \\
\hline B & 2 & 2,945 & 2.4 & 2.1 & 1.3 & 0.117 & 1 * RPM \\
\hline B & 3 & 6,020 & 2.6 & 2.3 & 1.5 & 0.11 & 2 * RPM \\
\hline C & 4 & 9,000 & 2.3 & 2.3 & 1.2 & 0.15 & 3 * RPM \\
\hline D & 5 & 12,200 & 2.3 & 2.6 & 1.1 & 0.04 & 4 * RPM \\
\hline D & 6 & 15,170 & 2.4 & 2.6 & 1.1 & 0.43 & 5 * RPM \\
\hline & & & & & & & \\
\hline & & & & & & & \\
\hline
\end{tabular}

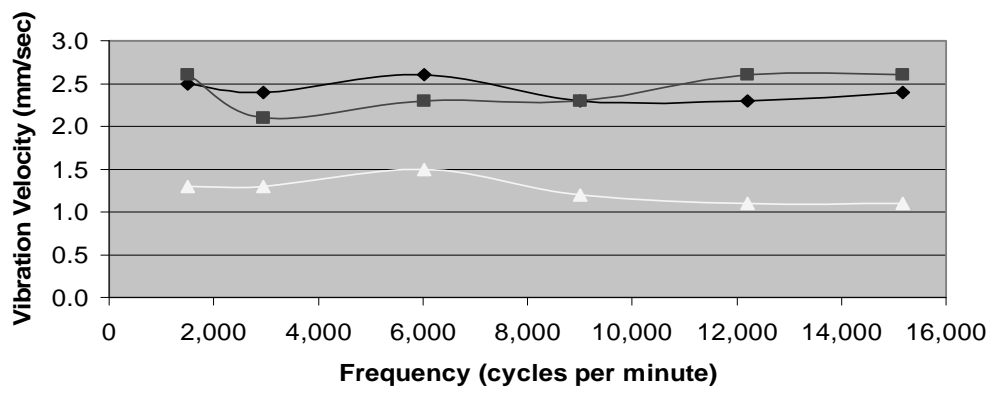

$\rightarrow-\mathrm{VH} \rightarrow-\mathrm{VV} \quad \mathrm{VA}$

Figure 8. Vibration velocities for the 1800-01A pump (AFE).

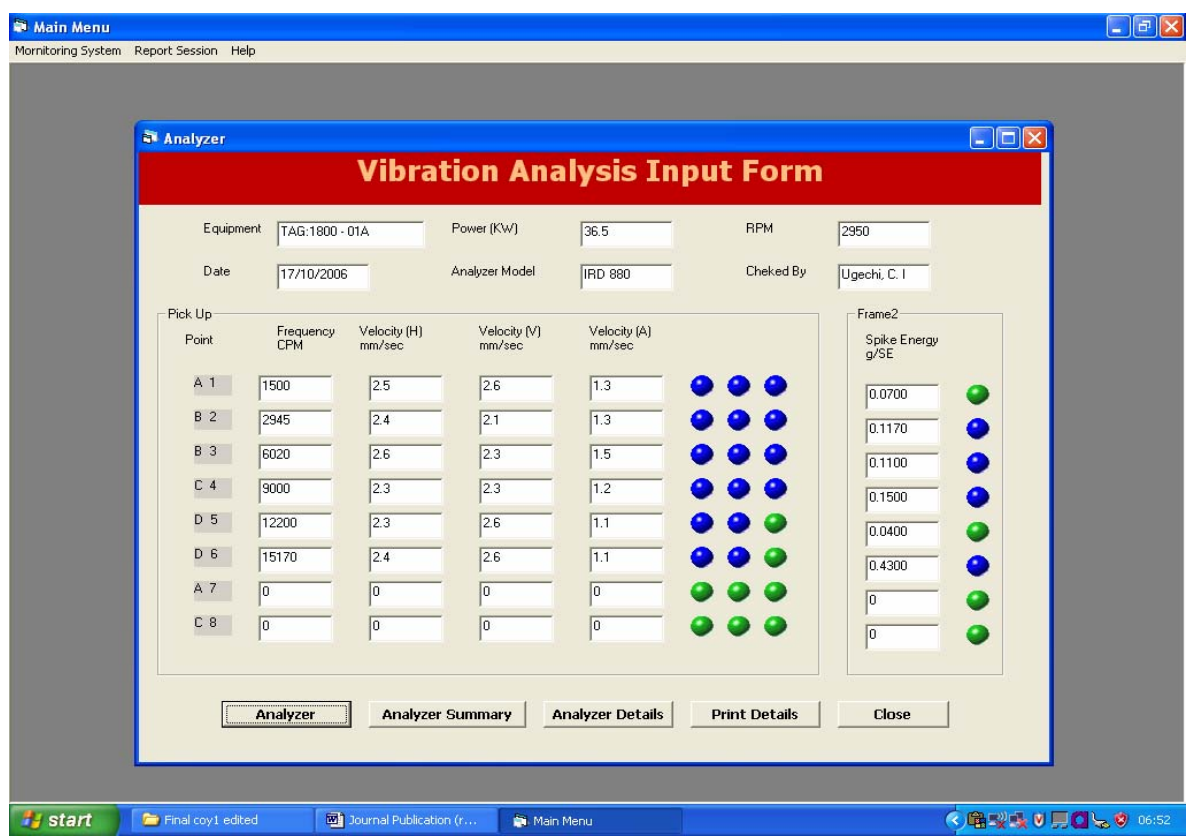

Figure 9. Computer screen presentation for the analysis after fault elimination (AFE). 


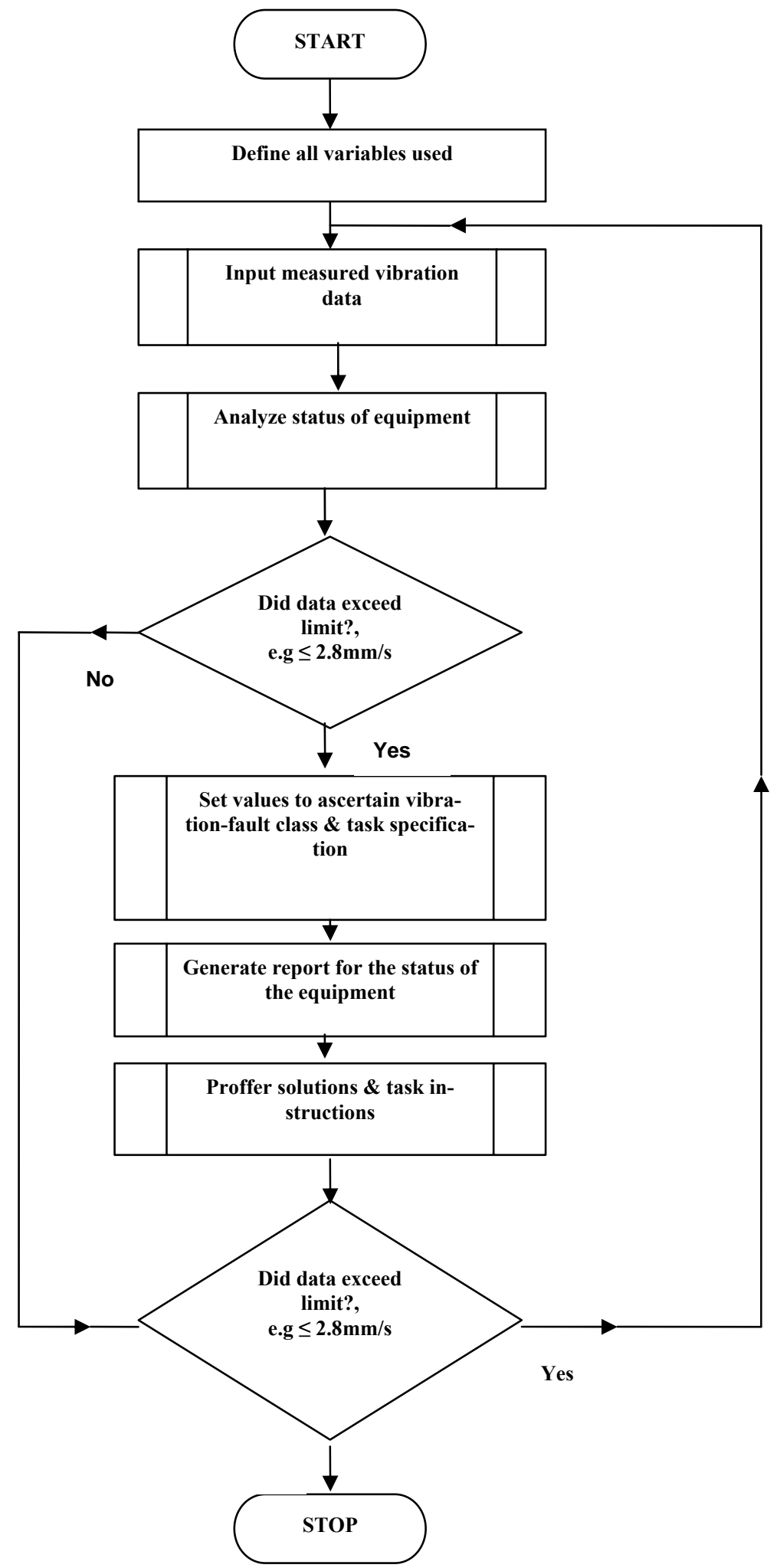

Appendix 1. predictive maintenance program flow-chart.

The task instructions were executed and the data collected after the fault elimination shown in Table 4 . The associated graph (i.e. Figure 8) showed almost smooth trends with a maximum of $2.6 \mathrm{~mm} / \mathrm{sec}$ radial vibration 
velocity amplitude and $1.5 \mathrm{~mm} / \mathrm{sec}$ amplitude in the axial direction, which suggested an acceptable working condition, had been achieved.

Results of the analysis of these data are shown in Figure 9 and confirmed that the condition of the pump was within acceptable range. This is evident in the displayed green and blue colours. Therefore the program did not proceed to a second phase of the analysis. Also comparing the data in Table 4 with specified maximum vibration-level of $3.0 \mathrm{~mm} / \mathrm{sec}$ for the pump, as recommended by the manufacturer, showed that the vibration values were within the acceptable range.

\section{Conclusions}

A diagnostic condition-based model that can be used for the PdM of rotary equipment has evolved from this study. The complexities involved in the analysis of vibration data have been simplified for the vibration analyst and PDM personnel. The high level of human error associated with the analysis of vibration data could also be reduced through this procedure. Faults of the rotating machine, identified through this analysis of its vibration characteristics, can be displayed numerately and graphically.

The results obtained from the model, which was developed using an $\mathrm{ANN}$, revealed that the approach is well suited to the diagnosis of vibration-based faults in centrifugal pumps. Though the model was validated using vibration data obtained from a centrifugal pump, it can be used to analyze vibration faults in other categories of rotating equipment. The model can also therefore be used for continuous real-time on-line condition monitoring.

\section{References}

[1] L. R. Higgins, "Maintenance engineering handbook," McGraw-Hill Book Company, New York, USA, pp. 2235, 1995.

[2] E. A. Ogbonnaya, "Condition monitoring of a diesel engine for electricity generation," M. Tech. Thesis, Department of Marine Engineering, Rivers State University of Science and Technology, Port Harcourt, Nigeria, p. 68, 1998.

[3] L. R. Contreras, C. Modi, and A. Pennathur, "Integrating simulation modelling and equipment condition diagnostics for predictive maintenance strategies-A case study," Proceedings of the 2002 Winter Simulation Conference, University of Texas, El Paso, USA, pp. 1-7, 2002.

[4] M, Salva, R. Hernandez, and C. Sanz, "Proposed of a method for implementing infrared-scanning inspection programs in merchant vessels," Marine Technology and Sname News, Vol. 41, No. 1, pp. 1-6, 2004.
[5] J. M.Moubray, "Maintenance management: A new paradigm, strategic technologies," Inc., Aladon Ltd, UK, pp. 7 -11, 2000. [Online] Available: http://www.maintenancere sources.com/RCM/Maintparadigm, July 29, 2006.

[6] A. Veltkamp, "Vibration introduction course: SKF condition monitoring, in computerized maintenance management system and enterprise resource planning," Nigerian Society of Engineers, Lagos, Nigeria, pp. 1.1-4.5, 2001.

[7] S. Jeff, PDM, "Secrets revealed: How to improve your PDM program or start one from scratch," $1^{\text {st }}$ Edition, Allied Reliability, Inc., Tulsa, Oklohoma, [Online] Available: http://www.alliedreliability.com, pp. 4-35, June 6 , 2006.

[8] E. A. Ogbonnaya, "Modelling vibration-Basic faults in rotor shafts of a gas turbine," $\mathrm{PhD}$ Thesis, Department of Marine Engineering, Rivers State University of Science and Technology, Port Harcourt, Nigeria, p. 251, 2004.

[9] B. E. Okah-Avae, "The science of industrial machinery and systems maintenance," Spectrum Books Ltd, Lagos, Nigeria, pp. 19-105, 1996.

[10] W. P. P. Ralph, "Maintenance management and control," in Handbook of Industrial Engineering: Technology and Operations Management, 3rd Ed., Inc. New York, USA, pp. 1611-1615, 2001.

[11] IRD Mechanalysis, "Vibration monitoring and analysis handbook," IRD Mechanalysis, Inc., Columbus, USA, pp. 1.7-5.7, 1993.

[12] J. T. Broch, "Mechanical vibration and shock measurement," $2^{\text {nd }}$ Ed., K. Larsen \& Son A/S, Denmark, pp. 197199, 1980.

[13] K. A. Oladejo and A. O. Oke, "Condition monitoring of a centrifugal pump," in Pump Maintenance, Arcedem Seminar Paper, Ibadan, Nigeria, pp. 6-10, 2005.

[14] E. P. Agbese and A. Mohammed, "Artificial neural network and their applications," Proceedings of First National Conference of the Department of Mechanical Engineering on Manufacturing Technology and Engineering in a Developing Economy, University of Uyo, Nigeria, May 2-3, pp 51-55, 2001.

[15] J. S. Carlton, C. G. Holland, M. J. Newbury, D. Rhoden, and D. A. Triner, "Recent operational experience and research relating to marine machinery condition monitoring," Trans IMarE, Vol. 109, No. 1, pp. 75-95, 1997.

[16] E. A. Ogbonnaya, K. D. H. Bob-Mannual, I. E. Douglas, and H. I. Hart, "Application of artificial neural networks to gas turbine rotor shaft faults diagnosis," Journal of Science and Technology Research, Vol. 3, No. 1, pp. 12-15, 2004.

[17] K. Farhad, A. P. Mehmet, and M. Ehsan, "A new generation motion-control system for twin-hull vessels using a neural optimal controller," Marine Technology and Sname News, Vol. 40, No. 3, pp. 168-180, 2003. 


\section{Appendix}

\begin{tabular}{|c|c|}
\hline \multicolumn{2}{|c|}{ Abbreviations and Nomenclature } \\
\hline AFE & After fault elimination \\
\hline $\mathrm{Al}$ & Artificial Intelligence \\
\hline ANN & Artificial neural-network \\
\hline a & vibration acceleration \\
\hline BS & British Standard \\
\hline $\mathrm{CM}$ & Condition monitoring \\
\hline cpm & Cycles per minute \\
\hline$f$ & vibration frequency \\
\hline G & Large machines having electric motors of above \\
\hline \multicolumn{2}{|c|}{$300 \mathrm{~kW}$ power } \\
\hline g-SE & Unit of spike energy \\
\hline ISO & International Standards Organization \\
\hline K & Small machines having electric motors of up to \\
\hline \multicolumn{2}{|c|}{ 15kW power } \\
\hline M & Medium machines having electric motors of be- \\
\hline tween & 5 and 300kW power \\
\hline MS/L & Measurement location \\
\hline $\mathrm{MS} / \mathrm{S}$ & Measurement sequence \\
\hline $\mathrm{N}$ & Number of hidden layers \\
\hline PdM & Predictive maintenance \\
\hline PM & Preventive maintenance \\
\hline
\end{tabular}

RMS Root mean square

RPM Revolutions per minute

$T \quad$ Turbo machines

VA Vibration velocity in axial direction $(\mathrm{mm} / \mathrm{sec})$

VB Visual Basic

$\mathrm{VH} \quad$ Vibration velocity in horizontal direction $(\mathrm{mm} / \mathrm{sec})$

$\mathrm{VV}$ Vibration velocity in vertical direction $(\mathrm{mm} / \mathrm{sec})$

v vibration velocity $(\mathrm{mm} / \mathrm{sec})$

$\mathrm{x} \quad$ vibration displacement $(\mathrm{mm})$

Z Number of output layers

$\Delta \mathrm{F} \quad$ Change in vibration frequency

$\triangle \mathrm{P} \quad$ Change in active power

$\Delta \mathrm{SE} \quad$ Change in equipment spike energy

$\Delta \mathrm{V} \quad$ Change in vibration velocity amplitude

$\mu \mathrm{m} \quad$ Micrometre

\section{Glossary:}

Dominant frequency: Frequency at which the largest vibration-amplitude occurs.

Field vibration-data: Measured vibration data collected from running machines.

Fundamental frequency: Basic repetition of the rotating equipment; i. e. the first harmonic. 